\title{
The Coronavirus Pandemic as a Sustainability Indicator of the Modern World Order
}

\author{
Barmatova S. Rezunova M. Ovchinnikova O.
}

\author{
Russian Academy of National Economy and Public Administration, Bryansk, Russia \\ *Corresponding author. Email: bsp@br.ranepa.ru
}

\begin{abstract}
The article is devoted to assessing the effects of the coronavirus pandemic for three social subjects representing different levels of the social system: economy, health care and individual. On the basis of the secondary analysis of the data taken from sociological and statistical studies of recent months, the authors pay attention to both the risks that have appeared due to the pandemic and the specifics of each subject responding to the risks. In accordance with the analysis the directions of comprehensive scientific researches that will be relevant for political decision-making and public administration in the post-pandemic era are also substantiated in the article.
\end{abstract}

Keywords: coronavirus pandemic, health care, risk society, economy, individual

\section{INTRODUCTION}

The coronavirus pandemic has become a "black swan" [1] for the whole world; it has predetermined and conditioned many processes of the present, significantly complicating and speeding them up.

The processes taking place in the modern world turn out a special social experience, which has not existed before either at the level of the social system or at the level of the individual (in view of the societal realia of modern times). The scientific community has reacted to the pandemic situation rather promptly, but there are no comprehensive interdisciplinary researches as yet, since the pandemic itself has not terminated, and the social consequences for many societal subjects (at both macro and micro-levels) have not been completed yet.

At the same time, it is important for both theoretical scientists and practical managers to understand which social facts and phenomena, caused by the coronavirus pandemic, should become the primary object(s) of comprehensive researches, as that would determine how rapidly and effectively the world as a whole and the Russian Federation, in particular, will be able to overcome the consequences of the pandemic.

\subsection{Theoretical Background and Hypotheses}

The theoretical background for the research, presented in this article, is the theory of risk society by $\mathrm{W} .{ }^{\circ}$ Beck and E. ${ }^{\circ}$ Giddens $[2,3]$. However, the problem itself, described and analysed in the paper, requires an interdisciplinary approach. From this point of view, when preparing the materials of the article, the authors relied on the theoretical evidence of both foreign and native scientists.

The hypotheses were formed as part of the assessment of the consequences of the COVID-19 pandemic separately for each social subject: economy, health care, and individual.

\section{Economy}

The format of the paper does not permit analysing in detail the global impact of the pandemic coronavirus on the world economy and the economy of the Russian Federation. At the same time the following quotation from the analytical report prepared by Central Research Institute for Health Organization and Informatics of Ministry of Health of the Russian Federation is taken as a hypothesis: "...It is quite possible that the main damage to the country's economy will not be caused by a drop in domestic production because of the coronavirus spread, or by government spending on the fight against COVID-19, or by measures to support the economy and the population, but by the negative impact of the coronavirus on the economies of three key centres: the United States, China, and the European Union.

It is their economies that will suffer from the coronavirus most of all, and it will result in a decline in demand and prices for the main products imported by Russia. Just as in 2008-2010 it will not be the crisis of the Russian economy, but the crisis of the economies of the developed Western countries and China, affecting our economy. In fact, this means that we will suffer the main losses due to the lack of effective measures of the developed Western countries to control the coronavirus"[4].

Health Care

The impact of the pandemic on the functioning and costs of health care system of the Russian Federation has turned out far from unambiguous.

The researchers note both positive and negative effects of this influence.

The positive ones are the high degree of mobilization of the Russian health care system when controlling coronavirus infection and the mobility of medical organizations when reorientating to medical care for 
coronavirus patients. This was largely determined by the following features of the Russian health care:

- the developed system of the state epidemiological service;

- the strong scientific potential that allows carrying out forward looking studies, creating test systems, vaccines, etc.;

- the existing well-functioning system of population vaccination, an antituberculosis vaccine $\mathrm{BCG}$, in particular;

- the high state share in the economy, having played a positive role in the rapid organization of production of necessary drugs, equipment, etc. in these circumstances;

- the dominant role of the state (municipal) healthcare sector which is more subject to the government control and regulation, having contributed to a more efficient change profiles, etc. by medical organizations;

- the main part of the largest private clinics being in fact "quasi-private" as they were created by the state enterprises and organizations (or with some state participation): by Russian Railways, RAO Unified Energy System of Russia, Gazprom, Rosneft, Bank, etc. [4].

The negative factors are the predicted increase in aggravation and complications of the chronic diseases that have not been treated due to the suspension of periodic health examination and prophylactic medical survey, planned medical care, or refusal to contact medical organizations because of the fear to be infected with COVID-19 there, etc.

Therefore, the hypothesis of the study is determined as follows: the health care service has become that very system subject (social institution), which effective functioning will results in $90 \%$ overcoming the pandemic. That is why significant financial resources were allocated for its financing, and the President of the Russian Federation paid special attention to its work.

Individual

Among the main challenges to the individual, generated by the pandemic, the following were mentioned in the scientific literature: social atomization due to division and isolation of individuals from each other owing to distancing, and the break-up of personal and social interactions; stress, psychosocial personality traumatization, disadaptation and disorganization of public conscience, normativity destruction, panic attacks, emergence of new concerns and, accordingly, new expectations, especially concerning inflation [5].

In our opinion, to assess the consequences of the COVID19 pandemic on an individual, in addition to the analysis of the challenges, it is necessary to pay attention to the most common social practices implemented by individuals during the pandemic. And in this sense, the particularly indicative ones are a) the practice of social volunteering; b) the practice of social self-sacrifice of doctors and middle-level medical personnel working in the "red zones".

Therefore, the following position was chosen as a hypothesis: the coronavirus pandemic did not reveal a fundamentally new type of social practices, but strongly contributed to activating those social resources of individuals that reflect the specifics of professional groups (doctors) and the national, primarily Russian, mentality (readiness for social service).

\section{METHODS}

Working on the materials of the article, the method of secondary analysis of the data obtained from sociological and statistical studies was used.

As a base for conducting the secondary data analysis the following studies carried out by various sociological research centres and organizations in the last 18 months (both before and during the COVID-19 pandemic) were addressed to:

- "Index of Happiness" in 2019 [6];

- Social Mood at the Stage of Normalization by Russian Public Opinion Research Center (VTsIOM), 22 July 2020 [7];

- Analytical report "The Impact of COVID-19 on the Situation in the Russian Healthcare Service"[4];

- Project CoronaFOM [8];

- Study of the social effects of the COVID-19 pandemic of the Sociological crisis centre [9].

- Research "Behavior Strategies of Yekaterinburg Residents in the Context of the Pandemic and the Growing Economic Crisis. On the basis of the research data of the Foundation "Socium" [10].

Besides, the materials of the VTsIOM expert discussion on freelancing [11], and scientific articles by leading Russian sociologists on precarization were analysed [12].

\section{RESULTS}

\section{Economy}

It is impossible to compare the economic risks for the Russian Federation with the economic risks for the developed Western countries and the United States in this article. We could just mark some aspects affecting these risks.

Firstly, the morbidity rate in the Russian Federation is much lower than, for example, in the United States. Therefore, the consequences are still less noticeable for the economy.

Secondly, Russia has encountered a number of economic problems later than many other countries (due to the slower rate of the coronavirus spread). Hence, it deals with these difficulties for a shorter period of time, so it suffers less damage.

Thirdly, measures are taken promptly, thus allowing more efficient distribution of financial inputs and control spending (although it is difficult to predict the final level of expenses). 
Table 1 Did or does any of the listed above happen to you during the period of self-isolation? (\% respondents in self-isolation)

\begin{tabular}{|c|c|c|c|}
\hline \multicolumn{2}{|l|}{ Negative consequences } & \multicolumn{2}{|l|}{ Positive consequences } \\
\hline & $\%$ & & $\%$ \\
\hline $\begin{array}{l}\text { I'm losing my physical form, my body condition is } \\
\text { getting worse }\end{array}$ & $29 \%$ & I have a better sleep & $28 \%$ \\
\hline $\begin{array}{l}\text { I've got some psychological problems - strong } \\
\text { depression, stress, negative feelings }\end{array}$ & $21 \%$ & I began to spend more time on physical exercises & $19 \%$ \\
\hline $\begin{array}{l}\text { I have a worse sleep, I don't get enough sleep more } \\
\text { often than before }\end{array}$ & $16 \%$ & $\begin{array}{l}\text { I began taking healthy meals, stopped eating } \\
\text { harmful foods }\end{array}$ & $12 \%$ \\
\hline $\begin{array}{l}\text { My health has become worse - I feel worse, on the } \\
\text { whole, my chronic diseases have worsened }\end{array}$ & $7 \%$ & I feel better psychologically and emotionally & $8 \%$ \\
\hline I started drinking more alcohol & $7 \%$ & I feel better physically, I have more energy & $8 \%$ \\
\hline & & $\begin{array}{l}\text { My physical form and my body condition is } \\
\text { getting better }\end{array}$ & $7 \%$ \\
\hline
\end{tabular}

\section{Health Care}

Evidently, there are new expenditures connected with purchasing ambulances, diagnostic equipment, ventilators, oxygen equipment, personal protective equipment, etc. However, a significant part of these expenses could be considered not as budget losses, but as investments in the branch, since the purchased vehicles, tomographs, analyzing devices, ventilators, oxygen plants (concentrators, ramps, etc.) will be used for a few more years. The same applies to a number of other resources. It is also important that many purchases (ambulances, etc.) agree with the planned ones within the framework of the National Project "Health Care".

Individual

According to the researches self-isolation negatively affects the physical well-being and psychological state of many respondents. $35 \%$ of the respondents faced some negative consequences in self-isolation. At the same time there are also those who feel better: they have a sound sleep, take healthy meals, and spend more time on physical exercises. $31 \%$ of the respondents experienced weight gain in self-isolation, and $9 \%$ experienced weight loss.

Table 1 shows that a) there are more positive options than negative ones; b) negative reactions are more focused on the emotional sphere (negative feelings, stress), positive ones - on rational implementation (healthy meals, physical exercises), etc.

This result can be considered more as a positive tendency, indicating that the population is coping with new societal realia determining the living space of an individual, though with higher social anxiety.

\section{DISCUSSION}

Anthony Giddens pointed out in his writings that risk should be considered from two points of view - negative and positive. "Risk is a dynamic mobilizing force in a society that seeks changes and wants to determine its own future, rather than leave it at the mercy of religions, traditions, or the freaks of nature" [13].
Taking into account this definition, we have a rational view on the "lessons of the pandemic", which can be identified by the following positions:

1. The pandemic has become the most effective test of the mobility and efficiency of the health system.

There will be a re-evaluation of health care as a social institution. According to some points of view, it has coped with the tasks, according to others - it has failed. However, this institution will gain a new significance and a new social position when the epidemic is over.

2. The COVID-19 pandemic has appeared to be a powerful indicator of the societal condition of an individual as a holder of social capital: the level of his/her stress and the stability of his/her social practices.

In spite of all the economic, social and political problems, over the past decades the humanity, and the Russians, in particular, has been staying in a certain "comfort zone" (as suggested by fairly high indicators of the happiness index [6] and feel-good index [7]).

The pandemic has proved the "fragility" of an individual's belief in his/her immunity to global risks, primarily, to those related to health threats.

At present health care will be different: it will become "... existential rather than egocentric in nature, in other words, it will be a matter of survival. People being afraid of the coronavirus will treat health not so much as a sign of a civilized lifestyle, but as a value of the highest order - and not only for themselves, but also for their relatives" [14].

At the same time, according to the results of VTsIOM, "... in June 2020 the feel-good index of Russians (added by the authors) accounted for 53 points, being 6 points higher than in May, and is equal to the feel-good index at the beginning of the year (in January 2020 it was 52 points) and during the two previous years (in June 2018 and 2019 it was 53 points)" [7].

So, it is significant that the average Russian does not display a pessimistic societal condition; as for some citizens the forced isolation, on the contrary, gave rise to both self-recognition and recognition of their families, especially children.

An increased degree of social anxiety is observed in the group of entrepreneurs and the self-employed who were 
most affected by the first wave of the pandemic, since these are the groups where the cases of layoffs and termination of business activities were the most numerous. Thus, according to the research, "... 27\% of them (entrepreneurs - added by the authors) say that their business has stopped, the activity had to be completely ceased, and $11 \%$ believe that it is forever. $29 \%$ of the entrepreneurs report that more than five people in their environment have lost jobs (the same with $13 \%$ of the population). $59 \%$ note that the financial situation of the family has worsened (the same with $43 \%$ of the population)" [15].

In our opinion, the coronavirus pandemic is rather a local risk for the business sector participants (first and foremost, for the hired workers). The growing process of employment precarization is much more significant; its consequences have not yet received sufficient scientific analysis in our country $[12,16]$.

3. The pandemic has sharpened the status issue (the influence on making socially significant decisions) of technology and social science in the modern world.

The matter is that the risk society was predicted by $\mathrm{W} .{ }^{\circ}$ Beck at the end of the last (XX) century [17].

A. Giddens marked, "To live in the era of 'late modernity' means to live in a world of fortuity and risk being the immutable companions of a system seeking to establish dominance over nature and reflexive creation of history" [3].

Describing a society with a natural state of risk, the scientist defines it as follows: "A risk society is a modern society, the most important characteristics of which are social, economic, political and cultural backgrounds causing institutional uncertainty, increasing fragmentation, chaos; lack of clear distinction between nature and culture; deletion of the boundaries between classes, nations, people; quantitative and qualitative increase of risks" [3].

The researches of the scientists and their forecasts in many ways were taken as a "pure science", and, as a result, humanity turned out to be not ready for a real risk such as the coronavirus pandemic; although the technology development makes it possible to form a fairly effective "safety factor" of the social system. All these technologies are more focused on the "service", market segment, rather than on the development of a protective shield of the social system.

Therefore, science needs, in our opinion, to look for new arguments to convey to the world the truth discovered by scientists.

4. The COVID-19 pandemic has also served as a touchstone for a number of scientific theories.

Thus, the pandemic has become a kind of response to the idea of trauma society (the theory of cultural trauma by P. Shtompka [19]) emphasized by some Russian sociologists (for instance, in the monograph of $\mathrm{Zh}$. Toshchenko "Society of trauma: between evolution and revolution (experience of theoretical and empirical analysis)" [18]). It has proved that in the risk situation the successful mobilization of human, managerial and other resources of the society does not depend on whether the society is a "society of trauma" (as $\mathrm{Zh}$. Toshchenko considered
Russia) or, on the contrary, a society that does not experience any "trauma" (there are a lot of examples - the United States, Italy, France - further down the list). The success and effectiveness of mobilization depends on the efficiency of managerial decision-making and political will.

\section{CONCLUSION}

Summing up the results of the analysis presented in this article, we can draw the following conclusions:

1. It is the social institutions and system subjects (industries, the labour market, the economic sphere, the health care sector, etc.) that more experience the consequences of the coronavirus pandemic.

2. The world will never be the same; and this factor makes it necessary not only to rethink the rules and parameters of social interactions, but also to develop a social policy that will allow the individual to create a "zone of social comfort" as quickly as possible, taking into account new societal realia.

Therefore, the topics of complex interdisciplinary research should be formed within the framework of these findings. There may be the following issues:

1. Systemic changes which are necessary for the Russian society and the Russian state.

2. Will the way out of the pandemic create new investment opportunities for the health system?

3. Possible scenarios for the development of the healthcare system.

4. The aspects that will influence the formation of social practices in the post-pandemic period.

It is just a small number of issues for complex interdisciplinary researches, and this list will continue to grow until the coronavirus is defeated, and humanity realizes that the existence of a risk society requires constant mobilization and a high degree of readiness of the social system to prevent risks and minimize their consequences. The science and effective public administration practice should promote to it.

\section{REFERENCES}

[1] N.N. Taleb, The Black Swan: The Impact of the Highly Improbable, Penguin, 2015, 446 p.

[2] U. Beck, World at Risk, Cambridge: Polity Press, 2009, 269 p.

[3] A. Giddens, Modernity and Self-Identity: Self and Society in the Late Modern Age, Stanford, Calif.: Stanford University Press, 1991.

[4] Analytical report "The impact of COVID-19 on the situation in the Russian Healthcare Service", V.I.

Starodubov (Ed.), Moscow: Central Research Institute for Health Organization and Informatics of Ministry of 
Health of the Russian Federation, 2020, 45p., Electronic resource.

[5] Russian society in conditions of self-isolation. Social effects and consequences of the COVID-19 pandemic, monograph, M.A. Vaskov (Ed.), N.Kh. Gafiatulina, V.V. Kasyanov, P.S. Samygin, S.I. ${ }^{\circ}$ Samygin, Moscow: KnoRus, 2020, 260 p.

[6] Happiness in Russia: monitoring, Electronic resource.

[7] Social attitudes at the stage of normalization, Electronic resource.

[8] The Project CoronaFOM, Electronic resource, https://covid19.fom.ru

[9] Study of the social effects of the COVID-19 pandemic, Rep.9, date of issue 29.04.2020 [Electronic resource] URL: https://pltf.ru/wpcontent/uploads/2020/04/svodka-9.pdf

[10] Behavior strategies of Yekaterinburg residents in the context of the pandemic and the growing economic crisis. On the basis of the research data of the Foundation "Socium", Yekaterinburg, 2020, 33 p., Electronic resource.

[11] Freelancing as a new economic or social reality? VTSIOM, 28.09. 2020, Electronic resource, https://www.facebook.com/wciom/

[12] Zh.T. Toshchenko, General and specific criteria of precarious employment (experience of empirical analysis), Sociological Research, 9, 2020,pp. 90-102.

[13] A. Giddens, Runaway World: How Globalization is Reshaping Our Lives, transl. by M. L. Korobochkin, Moscow, The Whole World, 2004, 116 p.

[14] A. Oslon, Now people do not understand well what will happen tomorrow, Izvestia, 28.05.2020, Electronic resource.

[15] The pandemic and small business, FOM, 24.05.2020, Electronic resource.

[16] A.V. Popov, T.S. Solovyova, Employment precarization: discussion on the essence and ways of measuring, Sociological Research. 9, 2020, pp. 103113.

[17] Risk society. Towards a New Modernity, Ulrich Beck; transl. by V. Sedelnik and N. Fedorova, Moscow, Progress-Tradition, 2000, $381 \mathrm{p}$.
[18] Zh.T. Toshchenko, Society of trauma: between evolution and revolution (experience of theoretical and empirical analysis), Moscow, All the World, 2019, 345 p.

[19] P. Shtompka, Social change as a trauma (article one), Sociological Research. 1, 2001, pp. 6-16. 